\title{
Eco-phytomonitoring in ensuring radiological safety of urban buildings
}

\author{
Alena Gorodnichaya ${ }^{1}$, Irina Glinyanova ${ }^{2, *}$, and Victoria Pogorelova ${ }^{1}$ \\ ${ }^{1}$ Kuban State Agrarian University, KubSAU, 350044, Krasnodar, ul. Kalinina d.13, Volgograd, Russia \\ ${ }^{2}$ Institute of Architecture and Construction, VolgSTU, 400074, ul. Academic 1, Volgograd, Russia
}

\begin{abstract}
In the future, the use of nuclear energy in national economy will rise. After accident at the Chernobyl nuclear power plant, staff of Fukushima 1 pay special attention to the safety of reactors, however, emergency situations are still possible. Eco-monitoring in natural and urban environments is carried out in order to determine the level of ecological pollution, including radioactive pollution. Therefore, studies in that direction are relevant and their relevancy is only increasing over the years. The aim of this study is to research migration and accumulation of ${ }^{90} \mathrm{Sr}$ in vegetative and generative plant organs: cherry-plum (Prunus cerasifera Ehrh) tree and stone fruit species, gooseberry (Ríbes úva-críspa) shrub. Objectives: 1) applying ${ }^{90} \mathrm{SrCl}_{2}$ to the soil, imitating precipation (field experiments); 2) planting: Prunus cerasifera Ehrh; Ríbes úva-críspa into artificially polluted by ${ }^{90} \mathrm{SrCl}_{2}$ soil; 3 ) growing and monitoring of studied plants in the artificially polluted by ${ }^{90} \mathrm{SrCl}_{2}$ soil. The level of pollution of experiment field reached $500 \mathrm{MBq} / \mathrm{m}^{2}$. The accumulation of ${ }^{90} \mathrm{Sr}$ in vegetative and generative organs of trees (Prunus cerasifera Ehrh) and shrubs (Ríbes úva-críspa) was researched. Experimental plots have been laid according to methodic of Dospekhov B.A. Measurements of beta-emitting nuclides activity in samples have been made using the "Progress" software on the USK "Gamma Plus" (beta-path) device. As the result of research it has been found that both plant species have been accumulating nuclides. In 2016 cherry-plum accumulated ${ }^{90} \mathrm{Sr}$ in the bark, wood, leaves and fruits 2.0 , 2.1, 2.6 and 2.6 times more accordingly than the gooseberry. As a result of the experiment, material, that can be used in eco-monitoring, was obtained to provide nuclear safety of urban properties in the territories, allocated for the construction of public and residential buildings.
\end{abstract}

\section{Introduction}

The growing prosperity of mankind requires an increase in energy production. One of the sources is nuclear energy. Operating reactors produce quite a lot of power at lower production costs, in comparison with thermal power plants.

Moreover, nuclear energy is rightly considered as the most safe national economy area regarding environmental protection [1,2]. Nevertheless, accidents at nuclear facilities have occurred, for example, at the Chernobyl nuclear power plant and Fukushima 1. Accidents with the release of radioactive pollution have occurred even earlier: in Windscale (England),

\footnotetext{
*Corresponding author: ecoris@yandex.ru
} 
Three Mile Island (USA), etc., but the consequences of Chernobyl and Fukushima 1 accidents have been much larger and more tragic [3-8]. There are plenty of researches of possible accumulation of nuclides in agricultural products due to land pollution [9-15], but the topic of bio-monitoring in ensuring of radioecological safety of urban properties has not been studied enough. The aim of this study is to examine migration and accumulation of ${ }^{90} \mathrm{Sr}$ in vegetative and generative organs of plants: cherry-plum (Prunus cerasifera Ehrh) and gooseberry (Ríbes úva-críspa). Researches have been conducted in field during 2010, 2014 -2016 years; ${ }^{90} \mathrm{SrCl}_{2}$ was artificially added to the soil.

The novelty of research is the possibility of bio-monitoring of urban property safety based on using plants of cherry-plum (Prunus cerasifera Ehrh) and gooseberry (Ríbes úva-críspa). The proposed monitoring option that can give an answer in short period of time - does the studied plot of land pose a threat to human life and health from the point of view of radioactive contamination or not. For the construction of residential, public and industrial buildings, the customer is given a certain land area, which should be comprehensively studied by specialists. Engineering surveys and local monitoring of various environmental components are carried out [16].

\section{Materials and methods}

The studies were conducted in the field on the black earth soil, leached, low humus, and heavy $[17,18]$. All work was done according to the field experiment methodology [1], under all conditions. For artificial soil surface contamination, ${ }^{90} \mathrm{SrCl}_{2}$ was used. The contamination of the experimental plot was $500 \mathrm{MBq} / \mathrm{m}^{2}$. Prunus cerasifera Ehrh and Ríbes úva-críspa were the studied crops in the experimental field that was created in 2008 . There were 2 plot variants in the area; option 1 - planting of Prunus cerasifera Ehrh seedlings ( 6 pcs.) in contaminated soil. The feeding area of seedlings was $6 \times 4 \mathrm{~m}$, option 2 - planting Ríbes úvacríspa bushes ( 6 pcs.) in contaminated soil. At the ends of the plot rows were protective plants -2 at each. [1]. The nutritional area of the seedlings was: $4 \times 4 \mathrm{~m}$. Number of iterations of the experiment in both variants is 6 .

Sampling from the studied plants was performed in 2010, 2014-2016. Plants were divided into organs and parts, dried in an oven at a temperature of $1050{ }^{\circ} \mathrm{C}$, weighed and grinded in MRP-1 or EM-ZA mills. Tests of grinded products based on radioactive contamination were done on a USK "Gamma Plus" device according to the methodic for measuring the activity of beta-emitting radionuclides in samples using the "Progress" software. The method was developed by GP RRIPTREM and approved by the State Standard of Russia on 05.05.1996. This methodic is fundamental in determining the activity values of beta-emitting radionuclides in a sample and allows to calculate the error of each measurement. To register beta radiation from a sample a beta spectrometric path with a scintillation detection unit (SDU) was used. To show samples, special aluminum cuvettes were used (Complex Universal Spectrometric "Gamma Plus", 1995). When monitoring the quantity of strontium90 in soil and plants, methodological guidelines were used (Methodological guidelines for determining the quantity of strontium-90 and cesium-137 in soil and plants, CINAO, 1985), GOST R 50801-95, as well as OST R 10070 -95 of soil. The methodic for the determination of strontium-90 in the soil of farmland (OST R 10070-95). The obtained results were processed by the methods of mathematical statistics according to Dospekhov B.A. [1].

\section{Results}

Due to the fact that different organs and parts of plants accumulate the pollutant differently, one of the tasks was to determine the ${ }^{90} \mathrm{Sr}$ quantity in the vegetative and generative organs of 
cherry-plum and gooseberry. The radionuclide quantity in the bark of the studied plants is shown in Figure 1. Because of the more powerful root system, the accumulation of the radionuclide in the cherry-plum bark in the first years of research was higher than in the gooseberry bark. However, during the research period, the difference in the ${ }^{90} \mathrm{Sr}$ quantity in the bark of the studied plants decreased: in 2010 it was 3.0 times, and in 2016 already 2.0 times. That is, according to the obtained experimental data, the accumulation of the nuclide in the cherry-plum bark has been practically absent in recent years, while it continues in the gooseberry. The explanation for the decrease in the accumulation of the nuclide in the cherryplum bark can be as follows: over time, the root system of the plant goes deeper into the soil; therefore, its contact with the nuclide located on the ground surface decreases. An increase in the aboveground mass also plays a role, as most of the nutrients are being absorbed by the plant from the deeper layers of the soil, and it is practically uncontaminated, that is, a gradual dilution of the pollutant in the plant's organs takes place. The dynamics of nuclide accumulation in the gooseberry bark is completely different. Due to the fact that the root system of Ríbes úva-críspa is much longer in the upper soil layer, where ${ }^{90} \mathrm{Sr}$ is located, its accumulation in the bark takes place during the entire period of research. The quantity of ${ }^{90} \mathrm{Sr}$ in the gooseberry bark from 2010 to 2016 changed 2.3 times, while in cherry-plum only 1.6 times (Fig. 1).

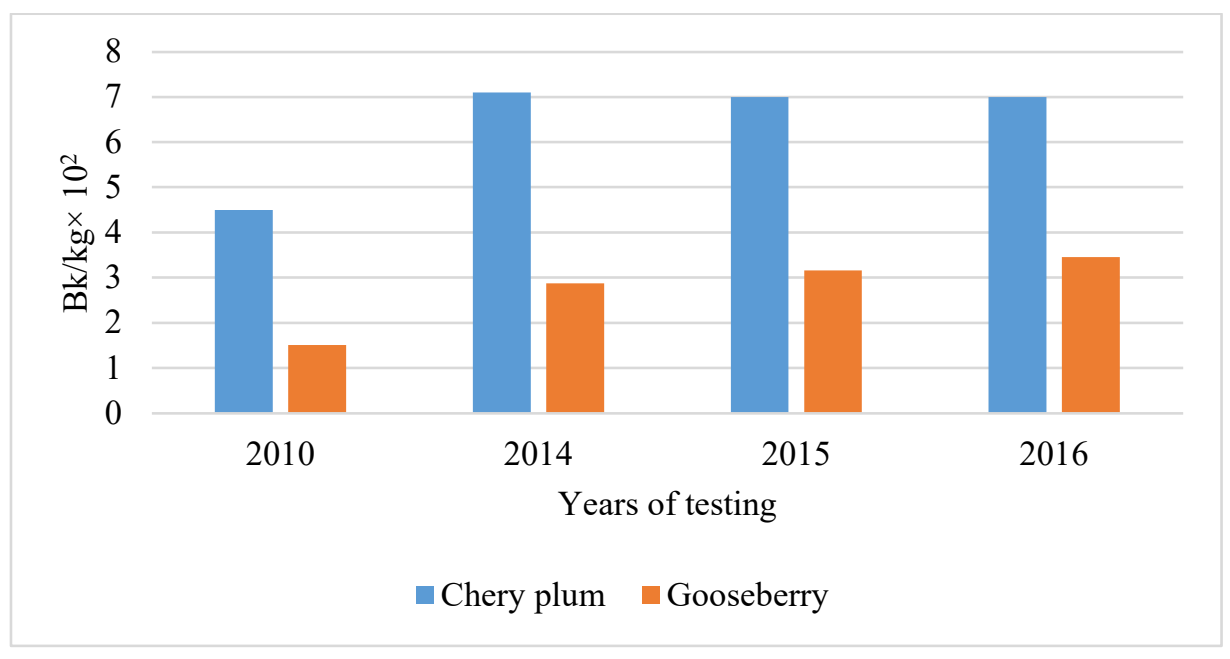

Fig. 1. The quantity of ${ }^{90} \mathrm{Sr}$ in the bark of the studied plants

The difference in the accumulation of radionuclide in the bark between cherry-plum and gooseberry amounted to the years of research: 2010, 2014, 2015,2016, respectively - 3.0; 2.5; 2.2 and 2.0 times.

Nevertheless, the radionuclide quantity in the cherry-plum bark in 2016 is higher than in the gooseberry bark.

In the process of studying the accumulation of ${ }^{90} \mathrm{Sr}$ in plants, its quantity in the wood was determined (Fig.2). 


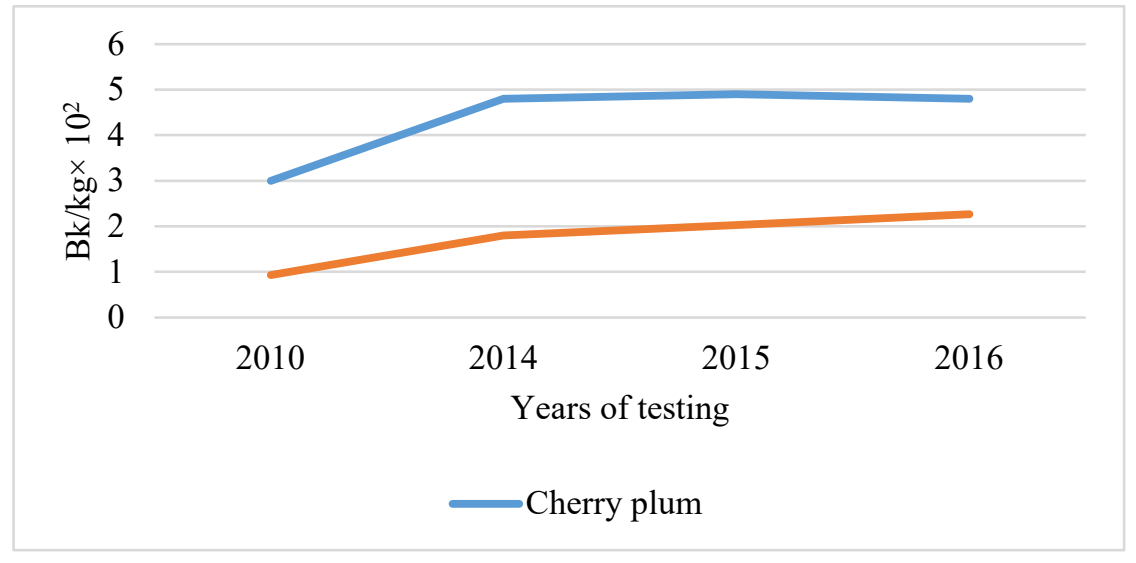

Fig. 2. The quantity of ${ }^{90} \mathrm{Sr}$ in the wood of studied plants

In the process of research, a difference has been found in the accumulation of the radionuclides of plum and gooseberry wood.

A high intensity dynamics of nuclide accumulation in cherry-plum wood was noted in the first research period, however, in recent years (2014-2016), accumulation was practically absent, while in gooseberry wood, nuclide accumulation continued in 2016 . The difference in ${ }^{90} \mathrm{Sr}$ accumulation in the wood of Prunus cerasifera Ehrh and Ríbes úva-críspa was established. According to the years of research $(2010,2014-2016)$, it is respectively $3.2 ; 2.7$; 2.4 and 2.1 times. Decrease in difference of the accumulation of nuclides in the wood of the studied plants is also observed. The root system of cherry-plum, unlike the gooseberry, gradually goes deeper into the soil, preventing close contact with the nuclide located in the upper soil layer. The root system of gooseberry is located in the top layer of soil, so the radionuclide continues to enter the plant. Therefore, the different location of the root system in the soil is one of the reasons for the observed tendency of decreasing difference in the nuclide quantity in the wood of the studied plants. Nevertheless, it has been noted that by 2016 , the cherry-plum accumulated more nuclide in the wood.

Leaves does the most important functions of plants [19,20]. It can accumulate various pollutants, including radioactive ones. However, to date, not much has been done to determine the quantity of the ${ }^{90} \mathrm{Sr}$ and accumulation dynamics in the leafage of the studied plants. Such studies were performed and the results are presented in Figure 3.

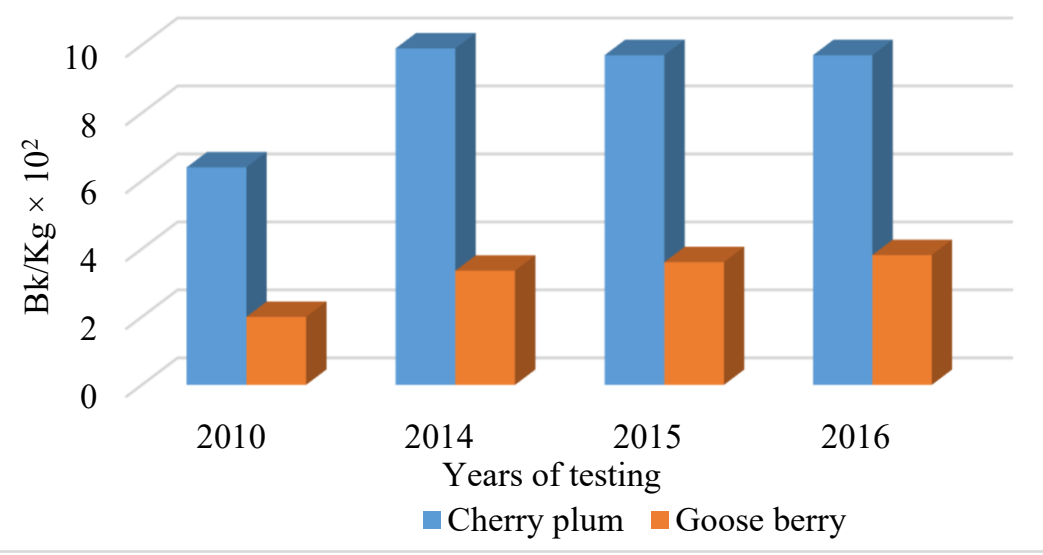

Fig. 3. The quantity of ${ }^{90} \mathrm{Sr}$ in leaves of studied plants 
As a result of the experiment performed in the field, it was found that the cherry-plum leaf contains more of the studied radionuclide than the gooseberry leaf and the difference for 2016 is 2.5 times. In 2010, the difference in ${ }^{90} \mathrm{Sr}$ accumulation in the leafage of the studied plants was 3.2 times, so there a tendency of decrease in difference compared to 2016 can be noticed. It was found that over the last 3 years of research $(2014-2016),{ }^{90} \mathrm{Sr}$ accumulation in the bark, wood and leaves of cherryplum was practically absent, unlike gooseberry. An explanation for this "behavior" of the radionuclide and its accumulation in the vegetative organs of the plant can be found in the following: firstly, over time, the radionuclide passes into a less mobile form; secondly, the different position of the root system in the soil and thirdly, increase in biomass of the plant itself.

One of the most important indicators for the accumulation of a radionuclide in plants is its quantity in fruits (Fig. 4).

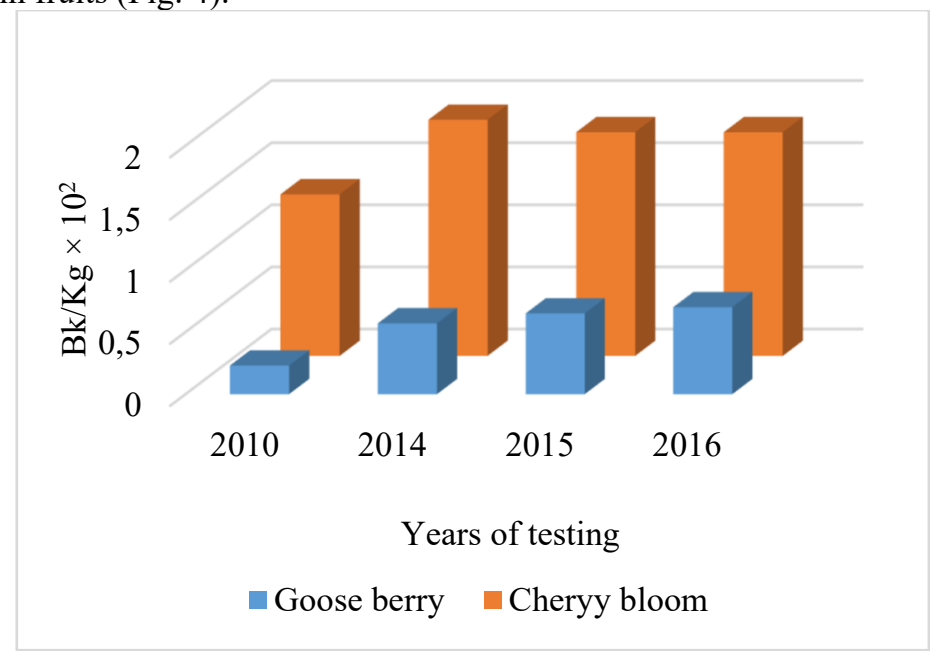

Fig. 4. Quantity of ${ }^{90} \mathrm{Sr}$ in fruits of studied plants

The economic value of the fruits of the studied plants for humans and their importance for animals are well-known. If the soil is polluted, the fruits can be contaminated, so one of the research tasks was to determine quantity of radionuclides in the fruits of cherry-plum and gooseberry.

Based on the obtained experimental material, we can conclude that the ${ }^{90} \mathrm{Sr}$ quantity in the fruits of the studied plants is not the same, and if in 2010 the difference was 5.7 times, then by 2016 it had decreased to 2.6 times. The tendency of intense accumulation of the nuclide in the fruits of cherry-plum in the initial period of research with a decrease by 2016 has been found. The accumulation of ${ }^{90} \mathrm{Sr}$ in gooseberry fruits is less intense, but it continued until the last year of research (2016).

\section{Discussion}

High intensity in the dynamics of nuclide accumulation in the vegetative and generative organs of cherry-plum in the first period of research was noted. However, in the last years of research (2014-2016), accumulation of ${ }^{90} \mathrm{Sr}$ in Prunus cerasifera Ehrh was practically absent, while the accumulation of nuclide continued in the vegetative and generative organs of gooseberry in 2016. A difference in the accumulation of ${ }^{90} \mathrm{Sr}$ was found in all studied organs of Prunus cerasifera Ehrh and Ríbes úva-críspa. Moreover, if in the initial period of research the difference in accumulation is high, then in the future there is a gradual decrease in 
difference of the accumulation of the nuclide. The root system of cherry-plum, unlike the gooseberry, goes deeper into the soil, preventing close contact with the nuclide located in the upper soil layer. The root system of gooseberry is located in the upper layer of soil, so the radionuclide continues to enter the plant throughout the research period. That is, the different position of the root system in the soil is one of the reasons for the observed tendency of decreasing difference in the nuclide quantity in the vegetative and generative organs of the studied plants.

\section{Conclusion}

While ${ }^{90} \mathrm{Sr}$ is located on the soil surface, its greatest accumulation in the bark, wood, leaves and fruits was found in cherry-plum (Prunus cerasifera Ehrh) rather than in gooseberry (Ríbes úva-críspa). This type of wood plant can be used to diagnose soil for radioactive contamination when examining the territory allocated for the construction of residential, public and industrial buildings. Gooseberry (Ríbes úva-críspa) accumulate nuclides in their vegetative and generative organs less intensively than plum. Nevertheless, it can also be used to diagnose soil for radioactive contamination, but in a more distant period after it is planted in the soil.

\section{References}

1. B. A. Dospekhov, Methodology of field experiment (Kolos, Moscow, 1968).

2. R.M. Aleksakhin, O.I. Bufatin et al, Radioecology of irrigated agriculture (Moscow, Energoatomizdat, 1985).

3. Yu.S. Sedunov, V.A. Borzilov, Physicomathematical modeling of regional transport in the atmosphere of radioactive substances as a result of the Chernobyl accident, Meteorology and Hydrology, 9, 5-10 (1989).

4. V. Grimas, G. Neumann, Studies of cesium-137 from the Chernobyl accident in a contaminated area at the Baltic sea, 4 Symp. int. radioecol. Cadarache "Impact accidents orig. nucl. Environ.”, 1, 122-130 (1988).

5. G. Lindner, M. Becker, Biological transfer and sedimentation of Chernobyl radionuclides in lake Constance, Large Lakes. Ecological structure and function, Springer-Vertag, 1990.

6. V.E. Sokolov, I.I. Ryabov, Ecological and genetic consequences of the Chernobyl accident, First International Working Group on Serious Accidents and Their Consequences (October 30-November 3, 1989, Dagomys) (Science, Moscow, 1990).

7. I.M. Bulavik, Cesium-137 pollution of the main elements of biogeocenosi, Abstract. doc. 1 Int. Conf. "Biological and radioecological consequences of the Chernobyl accident" (Cape Verde 10-18.09.1990),1990.

8. A.I. Scheglov, et al. Biogeochemistry of Chernobyl release radionuclides in forest ecosystems of the European part of the CIS, Radiats. Biology, radioecology, 36 (4), 437446 (1996).

9. A.I. Melchenko, Dependence of radionuclide migration in fruit cenosis in the soil horizon of leached chernozem from the depth of their occurrence, Proceedings of the Kuban State Agrarian University, 2 (11), 165-170 (2008).

10. A.I. Melchenko, et al., Accumulation of radionuclides in agricultural crops depending on the time of their contact with plants, Proceedings of the Kuban State Agrarian University, 4 (31), 157-162 (2011). 
11. A.I. Melchenko, et al., Dynamics of $90 \mathrm{Sr}$ accumulation in the vegetative and generative organs of various varieties of hazelnuts, Problems of regional ecology, 3, 51-56 (2016).

12. V.N. Naumkin, Agricultural production in the conditions of radioactive soil pollution, Achievements of science and technology of the agro-industrial complex, 10, 10-13 (1999).

13. V.M. Klechkovsky, About the behavior of radioactive fission products in soils, their entry into plants and accumulation in the crop, 2006.

14. L.A. Buldakov, A.K. Guskova, 15 years after the accident at the Chernobyl nuclear power plant, Radiation biology. Radioecology, 42 (2), 228-233 (2002).

15. A.I. Melchenko, et al., Accumulation of radionuclides in agricultural plants, depending on the physicochemical properties of radionuclides, Proceedings of the Kuban State Agrarian University, 1 (34), 91-99 (2012).

16. SP 47.13330.2012 Engineering surveys for construction. The main provisions. Actualized edition of SNiP 11-02-96. - 2013.

17. A.I. Simakin, Agrochemical characteristics of the Kuban chernozems and fertilizers, 1969.

18. B.F. Aparin, Soil Science (Academy, Moscow, 2012).

19. F.K. Tikhomirov, Botany (High school, Moscow, 2008).

20. P.M. Zhukovsky, Botany (Kolos, Moscow, 2002). 